\title{
Factors Associated with Chikungunya Relapse in Acapulco, Mexico: A Cross-Sectional Study
}

\author{
Ixtac Xochitl de la Cruz-Castro,, Elizabeth Nava-Aguilera, ${ }^{1}$ Arcadio Morales-Pérez, \\ Ángel Francisco Betanzos-Reyes, ${ }^{2}$ Miguel Flores-Moreno, ${ }^{1}$ Liliana Morales-Nava, ${ }^{1}$ \\ Alejandro Balanzar-Martínez, ${ }^{1, *}$ Felipe René Serrano-de los Santos, ${ }^{1}$ and Neil Andersson ${ }^{1,3}$
}

\begin{abstract}
Objective: To estimate the occurrence of self-reported chikungunya relapse and identify associated factors. Materials and Methods: A cross-sectional study in December 2015 included 1305 homes in eight urban clusters considered representative of Acapulco in southern Mexico. Administered questionnaires collated information on 5870 individuals, including sociodemographic variables, a history of chronic conditions, and the selfreporting of chikungunya. Bivariate and multivariate analyses relied on a cluster-adjusted Mantel-Haenszel procedure to identify the factors associated with chikungunya and its relapse.

Results: Some 66\% (3531/5870) of the population reported suffering chikungunya and 31.1\% (1098/3531) reported a relapse. Factors associated with relapse included the severity of the chikungunya case (odds ratio [OR]: 3.35; clusters adjusted 95\% confidence interval [95\% CIca]: 3.16-3.55); history of arthralgia (OR: 2.96; 95\% CIca: 2.27-3.86); age 30 years or older (OR: 1.85; 95\% CIca: 1.72-1.98); female (OR: 1.64; 95\% CIca: 1.42-1.90); and higher education households (OR: 1.18; 95\% CIca: 1.11-1.27).

Conclusions: The high occurrence of chikungunya and its relapse are a public health problem. The factors associated with relapse do not immediately suggest specific prevention strategies but emphasize the dire need for effective approaches to vector control.
\end{abstract}

Keywords: chikungunya, relapse, occurrence, associated factors

\section{Introduction}

$\mathbf{C}$ HIKUNGUNYA FEVER Is caused by an alphavirus (WHO 2017), transmitted mainly by the mosquitos Aedes aegypti and Aedes Albopictus, implicated now in various epidemics and in the transmission of the dengue and zika viruses (Her et al. 2009, Coffey et al. 2014). Given the wide distribution of these vectors in the Americas, the currently uninfected population is susceptible to chikungunya infection (PAHO/CDC 2011, Rivera-Ávila 2014). Relapse occurs generally 1 month after a symptom-free period after the initial infection (Couturier et al. 2012), due to persistence of the virus in the cells of musculoskeletal tissue; joint pain can be the same or greater than that experienced during the initial occurrence (Borgherini et al. 2008).
In 2015, 991,134 chikungunya cases were reported in the region of the Americas, with 11,468 of the 125,235 cases reported in Mexico confirmed by laboratory tests (PAHO/WHO 2015). With 1673 confirmed cases, the state of Guerrero was in second place nationally after Veracruz, with 2000 cases (SSA 2016a). After the 2015 outbreak (Rivera-Ávila 2014), the rapid spread of the epidemic in Guerrero received official recognition, presenting, according to the DirectorateGeneral for Epidemiology of the National Monitoring System, the highest number of cases in 2016 (SSA 2015a, 2016a). No circulation of the Zika virus occurred that year (SSA 2016b) and the incidence of dengue was low (SSA 2015b).

Little is known about factors associated with relapse of chikungunya. In the first experience with chikungunya in other countries, factors reported to date include the severity

${ }^{1}$ Centro de Investigación de Enfermedades Tropicales (CIET), Universidad Autónoma de Guerrero, Acapulco, Guerrero, México.

${ }^{2}$ Centro de Investigación Sobre Enfermedades Infecciosas (CISEI), Instituto Nacional de Salud Pública, Cuernavaca, Morelos, México.

${ }^{3}$ Department of Family Medicine, McGill University, Montreal, Canada.

*Deceased. 
of the case during the acute stage (initial severe pain), being $>40$ years of age, being female, comorbidities (a history of arthritis, arthralgia, and diabetes), and a depressed emotional state (Vijayakumar et al. 2011, Couturier et al. 2012, Kularatne et al. 2012, Gérardin et al. 2013). This study aimed to estimate the occurrence of chikungunya relapse and identify associated factors in Acapulco, as part of a bigger study.

\section{Materials and Methods}

\section{Sample}

A cross-sectional study contacted homes in eight urban clusters in Acapulco in December 2015. The purposive (nonprobabilistic) sampling sought to reflect urban average conditions in the municipality, without reference to the reported occurrence of dengue, chikungunya, and Zika. Survey sites have a high population density and residents have access to health care and education services, water supply, and basic sanitation. We included all households in each cluster.

\section{Interviewer training}

Interviewers selected had high school or higher education and received training in questionnaire administration, how to obtain informed verbal consent, and how to avoid missing data.

\section{Pilot test}

Before the application of the questionnaire, two pilot tests verified the questions were clear, pertinent, and useful for subsequent analysis. We also noted the time for administering the questionnaire, the levels and mechanisms of missing data, and logistics for fieldwork.

\section{Data collection}

Interviewers administered the questionnaire household by household, moving radially outwards from a central point. They asked about sociodemographic variables: age; gender; type of housing; gender of the informant; educational level and occupation of the head of the family; number of people living in the household; and whether the household was a beneficiary of the Prospera program that provides cash incentives for families who participate in government health, nutrition, and educational activities.

The questionnaire included variables related to chikungunya: the month in which the patient fell ill, where the patient was treated, whether the patient's condition was severe, whether the patient suffered chikungunya relapse and how many, and the number of people who had fallen ill. We also asked about comorbidities before contracting chikungunya, such as hypertension, diabetes, arthritis, and arthralgia. There is evidence that self-reported chikungunya cases are strongly related to those confirmed clinically or serologically (Staikowsky et al. 2008).

\section{Operational definition of key variables}

Chikungunya relapse. A reported recurrence of chikungunya symptoms (joint pain and inflammation) after 1 month having recovered from the disease, measured with the question: How many relapses have you experienced of chikungunya?
Severity of the disease. The respondent mentioned having fallen ill with chikungunya, this we determined with the question: Were you seriously ill?

\section{Age. Years of age as stated by the interviewee.}

History of arthralgia. Self-reported suffering joint pain before falling ill with chikungunya.

Educational level of the head of the family. Schooling declared by the respondent on being asked Until what year did the head of the family study?

Fieldwork. Before the interviews, we informed local authorities about the study and requested their authorization. Each interviewer received a sketch indicating their route and household coverage. After presenting themselves to each household, interviewers explain the objectives of study and request verbal consent, before administering the questionnaire.

Data capture and analysis. Trained operators entered data twice using the EpiData software (Lauritsen and Bruus 2005), with validation to minimize keystroke errors. Analysis relied on CIETmap open-source software (Andersson and Mitchell 2002) to obtain the simple frequencies for the variables. We calculated the odds ratio (OR) in bivariate and multivariate analyses adjusted by cluster through the MantelHaenszel procedure (Mantel and Haenszel 1959) in accordance with Lamothe (2011) to estimate cluster-adjusted $95 \%$ confidence interval (95\% CIca) (Cornfield 1956).

Multivariate analysis began with a saturated model including all variables associated with the outcome in the bivariate analysis, using step-wise deletion of the least significant association until all the remaining variables were significantly associated with the outcome at the $5 \%$ level. We tested for effect modification using Woolf's $\chi^{2}$ test for heterogeneity (Woolf 1955).

\section{Results}

We interviewed 1305 households in eight urban clusters in Acapulco, with women making up 72\% (943/1305) of the respondents. Information referred to 5870 people, with an average age of 33.6 ( $n=5870$, range: $0-90$; standard deviation [SD]: 22.162). The average number of people per household was 4.5 (5870/1305) (range: 1-16; SD: 2.24). Most housing, 79\% (1035/ $1305)$, was permanent with $15.3 \%$ (200/1305) semipermanent, $3.9 \%$ (51/1305) provisional, and 1.5\% (19/1305) not specified.

The educational level of the head of the family showed $15.7 \%(205 / 1305)$ not having studied, $16.1 \%(210 / 1305)$ stated that they had not finished primary education, $17.2 \%$ (226/1305) described having concluded primary education, $2.6 \%(34 / 1305)$ stated that they had not completed secondary education, $17.6 \%(230 / 1305)$ had concluded secondary education, $2.1 \%(28 / 1305)$ had not completed high school, $13.3 \%$ (174/1305) finished high school, 13.3\% (173/1305) had been educated to technical or professional level, and $1.9 \%(25 / 1305)$ did not know or did not answer.

Some 74\% (965/1341) of households were beneficiaries of the Prospera program, 24\% (313/1305) indicated an affiliation to the program, and $2 \%(26 / 1305)$ did not know or did not provide information in this regard. 


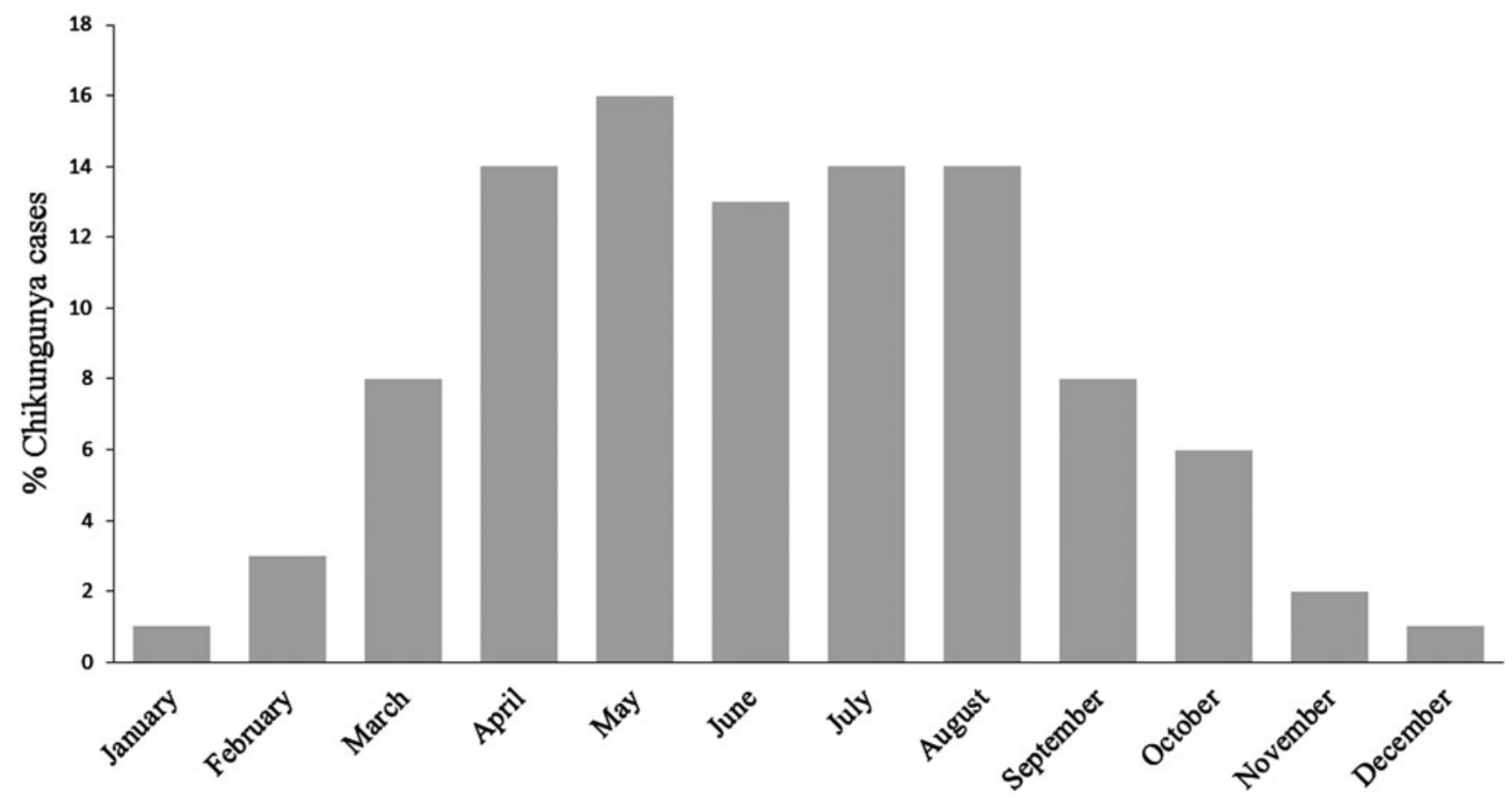

FIG. 1. Distribution of self-reported chikungunya cases per month in the urban area of Acapulco, Mexico, 2015.

No $<87 \%(1136 / 1305)$ of respondents reported one or more cases of chikungunya in 2015 (range: 1-13), with $66 \%$ (3531/5870) among household members covered by the questionnaire. Of these, $57.6 \%(2034 / 3531)$ were female and the average age was 36 years $(n=3531$, range: $0-90$; SD: 22.05). Of the chikungunya cases reported, $14.2 \%$ (500/3 531) were severe, with $60.9 \%$ (2149/3531) of respondents having sought public or private medical treatment, 36.9\% (1303/3531) having been treated at home, and 2.2\% (7/3531) did not know or did not answer. Asked about the type of medical conditions experienced before presenting chikungunya fever, 14.4\% (510/
$3531)$ reported hypertension, $10 \%(352 / 3531)$ reported diabetes mellitus, 8.1\% (286/3531) reported arthritis, and 8.0\% (284/ 3531) reported arthralgia. Most cases, 71.2\% (2405/3377), presented between April and August, 2015 (Fig. 1).

Of cases reported in the interviews, $31.1 \%$ (1098/3531) were described as having relapsed, of whom $65.8 \%$ (722/1098) were female. The average age was 40.69 years (range: 0-90; SD: 21.27). The distribution of relapse is shown in Fig. 2. The frequency of relapse was very similar when the respondent was male or female 29.2\% (229/783) and 32.6\% (863/2650), respectively.

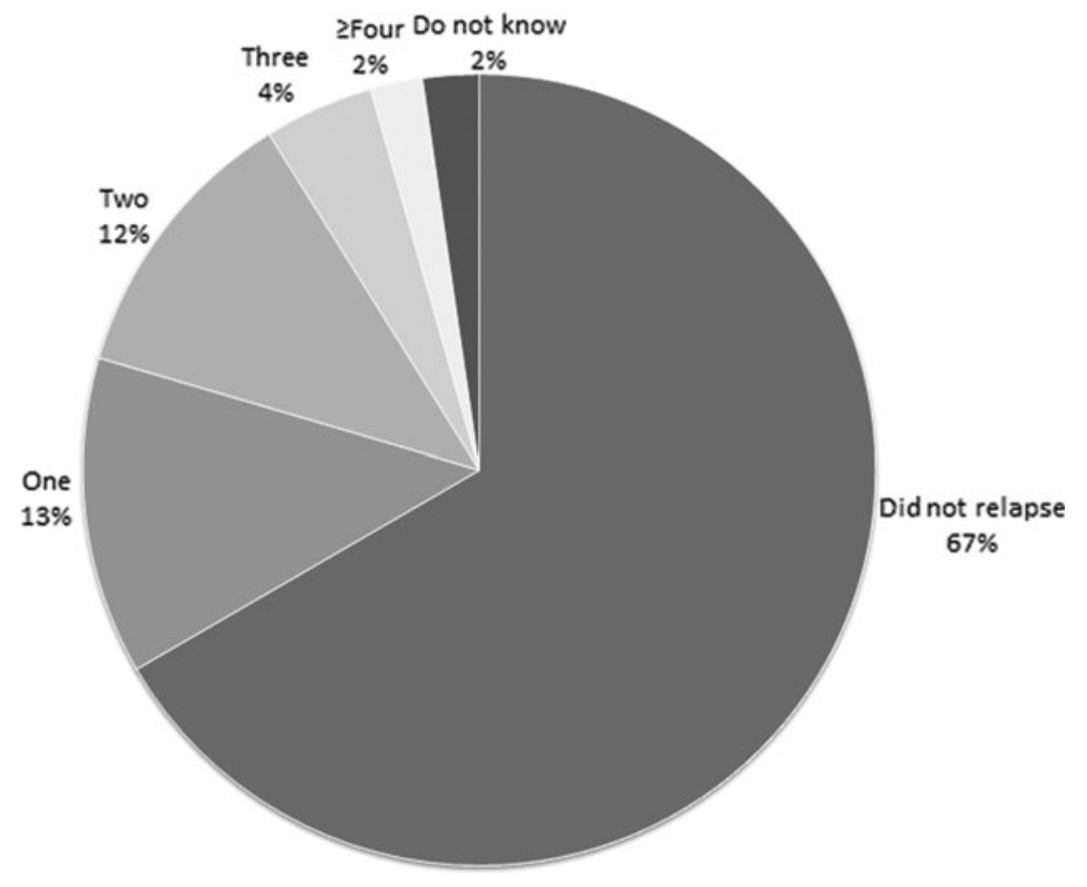

FIG. 2. Frequency of chikungunya relapse in the urban area of Acapulco, Mexico, 2015. 
Table 1. Bivariate Analysis of Factors Associated with Chikungunya Relapse in the Urban Area of Acapulco, Guerrero, MeXico 2015

\begin{tabular}{|c|c|c|c|c|c|}
\hline Variable & Levels & Proportion & Percentage & $O R$ & $\begin{array}{l}95 \% \\
\text { CIca }\end{array}$ \\
\hline \multirow[t]{2}{*}{ Age } & $\geq 30$ & $727 / 1941$ & 37.5 & 1.85 & $1.72-1.98$ \\
\hline & $<30$ & $369 / 1506$ & 24.5 & & \\
\hline \multirow[t]{2}{*}{ Gender } & Female & $722 / 1989$ & 36.3 & 1.64 & $1.42-1$. \\
\hline & Male & $374 / 1453$ & & & \\
\hline \multirow{2}{*}{ Place where treated } & Public or private sector & $781 / 2133$ & 36.6 & 1.84 & $1.52-2.2$ \\
\hline & At home & $309 / 1295$ & 23.9 & & \\
\hline \multirow{2}{*}{ Severe case } & Yes & 276/491 & 56.2 & 3.35 & $3.16-3.5$ \\
\hline & No & $816 / 2944$ & 27.7 & & \\
\hline \multirow{2}{*}{ Number of chikungunya cases in the home } & $<5$ cases & $707 / 2032$ & 34.8 & 1.39 & $1.09-1.77$ \\
\hline & $\geq 5$ cases & 388/1398 & 27.8 & & \\
\hline \multirow{2}{*}{ History of hypertension } & Yes & $200 / 502$ & 39.8 & 1.54 & $1.33-1$. \\
\hline & No & $889 / 2929$ & 30.4 & & \\
\hline \multirow{2}{*}{ History of diabetes } & Yes & $144 / 347$ & 41.5 & 1.60 & $1.11-2$. \\
\hline & No & $947 / 3078$ & 30.8 & & \\
\hline \multirow{2}{*}{ History of arthritis } & Yes & $157 / 282$ & 55.7 & 2.96 & $2.54-3$. \\
\hline & No & $936 / 3144$ & 29.8 & & \\
\hline \multirow[t]{2}{*}{ History of arthralgia } & Yes & $156 / 280$ & 55.7 & 2.96 & $2.27-3.8$ \\
\hline & No & $935 / 3138$ & 29.8 & & \\
\hline \multirow[t]{2}{*}{ Type of housing } & Permanent & $885 / 2696$ & 32.8 & 1.25 & $1.10-1.40$ \\
\hline & $\begin{array}{l}\text { Flimsy/provisional and } \\
\text { semipermanent }\end{array}$ & $204 / 724$ & 28.2 & & \\
\hline \multirow[t]{2}{*}{ Gender of the respondent } & Female & $863 / 2650$ & 32.6 & 1.17 & $1.07-1$. \\
\hline & Male & $229 / 783$ & 29.2 & & \\
\hline \multirow{2}{*}{ Educational level of the head of the family } & $\geq 5$ th grade primary & $781 / 2374$ & 32.9 & 1.18 & $1.11-1.27$ \\
\hline & $<5$ th grade primary/did not study & $300 / 1025$ & 29.3 & & \\
\hline \multirow[t]{2}{*}{ Occupation of the head of family } & Does not work & $394 / 1260$ & 31.3 & 0.97 & $0.84-1.1$ \\
\hline & Paid employment & $680 / 2133$ & 31.9 & & \\
\hline \multirow{2}{*}{ Number of people living in the home } & $<5$ people & $503 / 1407$ & 35.7 & 1.35 & $1.13-1.62$ \\
\hline & $\geq 5$ people & $595 / 2043$ & 29.1 & & \\
\hline \multirow{2}{*}{$\begin{array}{l}\text { Household is beneficiary of the Prospera } \\
\text { program }\end{array}$} & No & $771 / 2298$ & 33.6 & 1.26 & $1.10-1.4$ \\
\hline & Yes & $315 / 1099$ & 28.7 & & \\
\hline
\end{tabular}

OR, odds ratio; 95\% CIca, clusters adjusted 95\% confidence interval.

Table 1 shows the factors associated with chikungunya relapse in bivariate analysis. Table 2 shows the results of the multivariate analysis of factors associated with chikungunya relapse: severity of the initial episode, experiencing arthralgia before contracting chikungunya, being aged 30 years or

Table 2. Multivariate Analysis of Factors Associated With Chikungunya Relapse In the Urban Area of Acapulco, Mexico 2015

\begin{tabular}{lccccc}
\hline Variables & OR & $\begin{array}{c}\text { Adjusted } \\
\text { OR }\end{array}$ & $\begin{array}{c}95 \% \\
\text { CIca }\end{array}$ & $\begin{array}{l}\chi^{2} \\
\text { het }\end{array}$ & $\mathrm{p}$ \\
\hline $\begin{array}{l}\text { Severe case of } \\
\text { chikungunya }\end{array}$ & 3.35 & 3.05 & $2.50-3.71$ & 19.85 & 0.13 \\
$\begin{array}{l}\text { History of } \\
\quad \text { arthralgia }\end{array}$ & 2.87 & 2.20 & $1.68-2.89$ & 14.82 & 0.46 \\
$\begin{array}{l}\text { Age >29 years } \\
\text { Female }\end{array}$ & 1.84 & 1.66 & $1.41-1.94$ & 12.47 & 0.64 \\
$\begin{array}{l}\text { Educational level } \\
\text { of head of the } \\
\text { family } \geq 5 \text { th } \\
\text { grade primary }\end{array}$ & 1.66 & 1.57 & $1.34-1.84$ & 16.99 & 0.31 \\
$\quad$ & & 1.39 & $1.17-1.65$ & 16.55 & 0.34 \\
\hline
\end{tabular}

The factors revealed by the saturated model were type of housing, beneficiary of the Prospera program, number of people living in the household, number of chikungunya cases per household, place of treatment, high blood pressure, and having diabetes and arthritis. $\chi^{2}$ het, Woolf's $\chi^{2}$ test for heterogeneity. over, being female, and the head of the family having a high educational level.

\section{Discussion}

With a self-reported history of chikungunya of $66 \%$ in urban Acapulco, household informants reported relapse in one in every three cases. Factors associated with relapse were severity of the initial case, a history of arthralgia, age $>29$ years, female, and higher education households. The high occurrence of chikungunya reflects susceptibility of the Guerrero population. This study aimed to identify factors associated with chikungunya relapse in Acapulco.

A limitation in generalizing the results is purposive sample, selected in our study to reflect urban conditions with good access to health care but without reference to chikungunya, Zika, or dengue patterns. Although reported rates of chikungunya infection and recurrence were high, it is likely these rates were higher in less well to do population sectors.

We recognize the limits of self-reporting chikungunya infection and relapses; abstracted from an epidemic, people might confuse the signs and symptoms with other infections such as dengue or Zika. Given the high level of knowledge during the epidemic, and widespread familiarity with the alternatives, we consider this unlikely. The literature suggests self-reporting of chikungunya cases is probably reliable 
(Gérardin et al. 2008), since people present acute joint pain and disability in an epidemic context (PAHO/CDC 2011, PAHO/ WHO 2017). Staikowsky et al. (2008) reported that there were no significant differences between self-reported chikungunya cases and those cases confirmed clinically or serologically.

Our measured occurrence of chikungunya in this previously unaffected population was similar $(63 \%$ 209/331) to that in the Comoros (Sergon et al. 2007), and higher (38.9\%) than that reported by Staikowsky et al. (2008). Another study in Kenya reported $75 \%$ affected (Sergon et al. 2008). As in Mexico, these results refer to the first introduction of the virus. Authors reporting on re-emergence of chikungunya occurrences suggested rates between $22.3 \%$ and $36.9 \%$ (Balasubramaniam et al. 2011, Chattopadhyay et al. 2016).

The occurrence of chikungunya relapse in our study was similar to that reported in other new introduction of the virus, for example, by Gerardin et al. (2013), who observed that $32.1 \%(111 / 346)$ of chikungunya patients presented relapse. Other studies have reported higher relapse rates (48.9 and 72\%) (Staikowsky et al. 2008, Couturier et al. 2012), and a lower relapse rate (21\%) (Borgherini et al. 2008).

Consistent with the literature about outbreaks after the first introduction of chikungunya virus, we found the severity of the chikungunya case associated with relapse. Gerardin et al. (2013) found that the initial severity of the rheumatic symptoms caused by chikungunya increased the risk of relapse (OR 3.6; 95\% CI: 1.5-8.2).

We found that a history of arthralgia associated with relapse, similar to Couturier et al. (2012), who observed that chikungunya patients with rigid or inflamed joints had a greater risk of relapse. This could be due to the immune response and osteodegenerative processes. This study also confirmed the effect of age, wherein chikungunya relapse is associated with ages $>29$ years. Gerardin et al. (2013) found people between 45 and 59 years of age at higher risk of chikungunya relapse (OR 2.9; 95\% CI: 1.0-8.6), the risk increasing again over the age of 59 years (OR 10.4; 95\% CI: 3.5-31.1). The increased risk with age might be due to comorbidities (Couturier et al., 2012). Vijayakumar et al. (2011) reported on re-emergence of chikungunya that patients $>40$ years had a higher risk of relapse (OR 1.26; 95\% CI: 1.03-1.54).

Compatible with other studies, we found women and girls at higher risk of relapse, a result similar in a re-emergent outbreak that was found by Kularatne et al. (2012) (OR 1.53; 95\% CI: 1.04-2.29). This may be related to higher activity levels of female household members (food preparation, washing and ironing of clothes, household cleaning, and child and elderly care). We also found higher educational level associated with relapse, although we could not confirm this in the published literature. We do not rule out a reporting bias, with higher educated households being more informed about chikungunya and the epidemic. If such a bias exists, it implies underreporting in lower education households.

Despite long-standing efforts to control A. aegypti, the high levels of chikungunya were because the population had no immunity in their first contact with the virus. The high rate of relapse affects quality of life, a problem that made worse by the fact that it frequently occurs during the productive stage of life, with implications in an individual, family, employment, and health context. The factors we found associated with chikungunya relapse are related to personal conditions, implying a more vulnerable segment of the population gets affected.
Acapulco has a predominantly subhumid warm climate with average annual temperature of $22-28^{\circ} \mathrm{C}$ (INEGI 2015). Our results may be relevant to populations living in similar urban areas.

\section{Conclusions}

The high occurrence and relapse of chikungunya confirm that this disease is a public health problem of note. The factors associated suggest relapse affects vulnerable population segments and we note possible under-reporting of relapse in households with lower levels of education. Our study adds to the urgent call for effective prevention and control of A. aegypti, something that is not happening using current pesticide-based approaches, but that is possible with community-engaged approaches (Andersson et al. 2015).

\section{Author Disclosure Statement}

No conflicting financial interests exist.

\section{Funding Information}

This study was funded by the Fondo Institucional Consejo Nacional de Ciencia y Tecnología (CONACYT), Mexico, Convocatoria Proyectos de Desarrollo Científico para Atender Problemas Nacionales 2013, grant no. 212982.

\section{References}

Andersson N, Mitchell S. CIETmap: Free GIS and epidemiology software from the CIETgroup, helping to build the community voice into planning. In: World Congress of Epidemiology, Montreal Canada, August 2002.

Andersson N, Nava-Aguilera E, Arostegui J, Morales-Pérez A, et al. Evidence based community mobilization for dengue prevention in Nicaragua and Mexico (Camino Verde, the Green Way): Cluster randomized controlled trial. BMJ 2015; 351:h3267.

Balasubramaniam SM, Krishnakumar J, Stephen T, Gaur R, et al. Prevalence of Chikungunya in urban field practice area of a private medical college, Chennai. Indian J Community Med 2011; 36:124-127.

Borgherini G, Poubeau P, Jossaume A, Gouix A, et al. Persistent arthralgia associated with chikungunya virus: A study of 88 adult patients on Reunion Island. Clin Infect Dis 2008; 47:469-475.

Chattopadhyay S, Mukherjee R, Nandi A, Bhattacharya N. Chikungunya virus infection in West Bengal, India. Indian $\mathbf{J}$ Med Microbiol 2016;34:213-215.

Coffey LL, Failloux AB, Weaver SC. Chikungunya virusvector interactions. Viruses 2014; 6:4628-4663.

Cornfield J. A statistical problem arising from retrospective studies. Proc Berkeley Symp 1956; 4:135-148.

Couturier E, Guillemin F, Mura M, Léon L, et al. Impaired quality of life after chikungunya virus infection: A 2-year follow-up study. Rheumatology (Oxford) 2012; 51:1315-1322.

Gérardin P, Fianu A, Michault A, Mussard C, et al. Predictors of Chikungunya rheumatism: A prognostic survey ancillary to the TELECHIK cohort study. Arthritis Res Ther 2013; 5:R9.

Gérardin P, Guernier V, Perrau J, Fianu A, et al. Estimating Chikungunya prevalence in La Reunion Island outbreak by serosurveys: Two methods for two critical times of the epidemic. BMC Infect Dis 2008; 8:99.

Her Z, Kam YW, Lin RT, Ng LF. Chikungunya: A bending reality. Microbes Infect 2009; 11:1165-1176. 
INEGI (Instituto Nacional de Estadística y Geografía). Instituto Nacional de Estadística y Geografía. Anuario Estadístico y Geográfico de Guerrero 2015. Available at http://internet .contenidos.inegi.org.mx/contenidos/productos/prod_serv/con tenidos/espanol/bvinegi/productos/nueva_estruc/anuarios_2015/ 702825076900.pdf

Kularatne SA, Weerasinghe SC, Gihan C, Wickramasinghe S, et al. Epidemiology, clinical manifestations, and long-term outcomes of a major outbreak of chikungunya in a hamlet in Sri Lanka, in 2007: A longitudinal cohort study. J Trop Med 2012:639178.

Lamothe G. Adjusting the Mantel Haenszel test statistic and odds ratio for cluster sampling. BMC Health Serv Res 2011; 11(Suppl. 2):S15-Annex.

Lauritsen JM, Bruus M. EpiData (Version). A Comprehensive Tool for Validated Entry and Documentation of Data. Odense, Denmark: The EpiData Association, 2003-2005.

Mantel N, Haenszel W. Statistical aspects of the analysis of data from retrospective studies of disease. J Natl Cancer Inst 1959; 22:719-748.

PAHO/CDC (Pan American Health Organization/Centers for Disease Control and Prevention). Preparedness and Response for Chikungunya Virus: Introduction in the Americas. Washington, D.C: PAHO, 2011. Available at https://www.paho.org/ hq/index.php?option $=$ com_content $\&$ view $=$ article $\& i d=3545$ : 2010-preparedness-response-chikungunya-virus-introductionamericas \&Itemid=39837\&lang=en

PAHO/WHO (Pan American Health Organization, World Health Organization). Number of Reported Cases of Chikungunya Fever in the Americas, by Country or Territory 2015. (to week noted) Epidemiological Week/EW 52, 2015. 2015. Available at http://www.paho.org/hq/index.php?option= com_topics\&view=article\&id=343\&Itemid=40931\&lang=en

PAHO/WHO (Pan American Health Organization, World Health Organization). Frequently asked questions about chikungunya. 2017. Available at www.paho.org/hq/index.php? option=com_content $\&$ view=article $\&$ id $=9260 \% 3$ A2014-preg untas-respuestas-sobre-chikungunya $\&$ catid=908\%3Aviral-dis eases-home\&lang=en

Rivera-Ávila RC. Chikungunya fever in Mexico: confirmed case notes on the epidemiologic response. Salud Publica Mex 2014; 56:402-404.

Sergon K, Njuguna C, Kalani R, Ofula V, et al. Seroprevalence of chikungunya virus (CHIKV) infection on Lamu Island, Kenya, October 2004. Am J Trop Med Hyg 2008; 78:333-337.

Sergon K, Yahaya AA, Brown J, Bedja SA, et al. Seroprevalence of Chikungunya virus infection on Grande Comore Island, union of the Comoros, 2005. Am J Trop Med Hyg 2007; 76:1189-1193.

SSA (Health Secretariat). Updated table "Confirmed cases of Chikungunya Fever”. Epidemiological Week/SE 41 of 2015;
Internet database 2015. Director General of Epidemiology, National Epidemiological Surveillance System, SSA, CDMX, Mexico. 2015a. Available at https://www.gob.mx/salud/accionesy-programas/direccion-general-de-epidemiologia

SSA (Health Secretariat). Epidemiological Overview of Dengue Fever and Dengue Hemorrhagic Fever. Information published in Epidemiological Week 49, 2015. Director General of Epidemiology, National Epidemiological Surveillance System. Special System for the Epidemiological Surveillance of Dengue. 2015b. Available at https://www.gob.mx/cms/uploads/ attachment/file/42542/Pano_dengue_sem_49_2015.pdf

SSA (Health Secretariat). Updated table of confirmed cases of Chikungunya Fever preliminary closure 2015: Internet database 2016. Director General of Epidemiology, National Epidemiological Surveillance System, SSA, CDMX, Mexico. 2016a. Available at http://www.epidemiologia.salud.gob.mx/ doctos/avisos/2016/chik/DGE_CHIK_CASOSYDEF_SEM05_ 2016.pdf

SSA (Health Secretariat). Zika's Epidemiological Surveillance System Guidelines for Epidemiological Surveillance and Laboratory Diagnosis of Zika Virus Infection (version 3). Health Secretariat 2016. Director General of Epidemiology, National Epidemiological Surveillance System, SSA, CDMX, Mexico. 2016b. Available at https:/www.gob.mx/cms/uploads/ attachment/file/207354/lineamientos_ve_y_lab_virus_zika.pdf

Staikowsky F, Le Roux K, Schuffenecker I, Laurent P, et al. Retrospective survey of Chikungunya disease in Réunion Island hospital staff. Epidemiol Infect 2008; 136:196-206.

Vijayakumar KP, Nair Anish TS, George B, Lawrence T, et al. Clinical profile of chikungunya patients during the epidemic of 2007 in Kerala, India. J Glob Infect Dis 2011; 3:221-226.

WHO (World Health Organization). Chikungunya. Newsroom. World Health Organization Media Center, Geneva, Switzerland, 2017. Available at https://www.who.int/news-room/ fact-sheets/detail/chikungunya

Woolf B. On estimating the relation between blood group and disease. Ann Hum Genet 1955; 19:251-253.

Address correspondence to: Elizabeth Nava-Aguilera Centro de Investigación de Enfermedades Tropicales (CIET) Universidad Autónoma de Guerrero Calle Pino s/n, Colonia El Roble Acapulco C.P. 39640 Guerrero México

E-mail: enava@ciet.org 